\title{
Global regularity of 3D tropical climate model with fractional diffusion and nonlinear damping
}

\author{
Xiaoli Chen ${ }^{1}$ and Yaqi Wan $^{2}$ \\ ${ }^{1}$ Jiangxi Normal University \\ ${ }^{2}$ Jiangxi Normal University Yaohu Campus
}

February 12, 2022

\begin{abstract}
This paper investigates the three dimensional tropic climate equations with fractional diffusion and nonlinear damping. The global exixtence and unique strong solutions of the tropic climate equations have been build under the assumption that initial data $\$\left(\mathrm{u}_{-} 0, \mathrm{v}_{-} 0, \backslash\right.$ theta_0 $) \backslash$ in $\mathrm{H}^{\wedge} 1\left(\backslash \mathrm{R}^{\wedge} 3\right) \backslash$ times $\mathrm{H}^{\wedge} 1\left(\backslash \mathrm{R}^{\wedge} 3\right) \backslash$ times $\mathrm{H}^{\wedge} 1\left(\backslash \mathrm{R}^{\wedge} 3\right) \$$ with $\$ \backslash$ alpha $>1, \backslash \max (1, \backslash$ frac $\{\mathrm{p}+4\}\{2 \mathrm{p}\})<\backslash$ beta, $\backslash$ gamma $<1+\backslash \operatorname{frac}\{3\}\{\mathrm{p}+1\} \$$ and $\$ \mathrm{p}, \mathrm{q}>3 \$$.
\end{abstract}

\section{Hosted file}

global regularity for 3D tropic climate model-2022.pdf available at https://authorea. com/users/335308/articles/556161-global-regularity-of-3d-tropical-climate-model-withfractional-diffusion-and-nonlinear-damping 